\title{
Comparison of Two Protocols of Agar Gel Immunodiffusion (AGID) Used to Diagnose of Equine Infectious Anemia (EIA)
}

\author{
Maria do Rosário Oliveira da Cunha Beltrão ${ }^{1^{*}}$, Cid Aristóteles de Siqueira Alencar2, \\ Adriana Soares Leite ${ }^{2}$, Leonardo Tavares Freitas ${ }^{2}$, Julianne Cortizo Gonzalez ${ }^{1}$, \\ Vania Lucia de Assis Santana ${ }^{2}$, Hélio Cordeiro Manso-Filho ${ }^{1}$ \\ ${ }^{1}$ Department of Veterinary Medicine, Federal Rural University of Pernambuco, Recife, Brazil \\ ${ }^{2}$ National Animal and Plant Laboratory, Ministry of Agriculture, Livestock and Food Supply, Recife, Brazil \\ Email: rosariobeltrao@yahoo.co.uk
}

Received 27 May 2015; accepted 21 July 2015; published 24 July 2015

Copyright (C) 2015 by authors and Scientific Research Publishing Inc.

This work is licensed under the Creative Commons Attribution International License (CC BY).

http://creativecommons.org/licenses/by/4.0/

c) (i) Open Access

\section{Abstract}

The aim of the present study was to compare two protocols of Agar Gel Immunodiffusion (AGID) that can be used to diagnose Equine Infectious Anemia (EIA). Different volumes of reagents and support for agar gel were used, as recommended by the Ministry of Agriculture, Livestock and Food Supply (MAPA) and the World Organization for Animal Health (OIE). Equidae sera samples (n $=1000$ ) were tested using a national commercial kit and different volumes (i.e. $25 \mu \mathrm{L}-$ MAPA and $50 \mu \mathrm{L}-0 \mathrm{IE})$ of reagents and standard sera. Antigen was used as recommended by MAPA. The results were assessed by two operators, 48 hours after beginning the test. At the end of the experiment, a Kappa index of 1 was obtained by the operators, for the interpretation of the results and for the different volumes of reagents used. Similar results of agreement (Kappa index $=1$ ) were obtained when using slides or Petri dishes as support for the agar gel. In both cases, an almost perfect agreement was achieved, suggesting that the use of different supports does not affect the results. These findings indicate that both protocols (MAPA and OIE) can be used to diagnose EIA.

\section{Keywords}

Horses, Equids, EIA, Diagnosis, AGID, Serology

\footnotetext{
${ }^{*}$ Corresponding author.
} 


\section{Introduction}

Equine Infectious Anemia (EIA) is an important viral disease that affects animals of the family Equidae. The virus (EIAV) that causes this disease belongs to the family Retroviridae, of the genus Lentivirus, and is distributed worldwide [1] [2].

According to the World Organization for Animal Health (OIE), EIA is a disease that requires immediate notification [3]. Considering that more than $95 \%$ of infected animals are asymptomatic, as well as the fact that there is no available cure, vaccine or effective treatment, laboratory diagnosis plays an important role in disease control and prevention. The official program of control determines the euthanasia of infected animals [4].

Agar Gel Immunodiffusion (AGID) is a serological test that the OIE and the Ministry of Agriculture, Livestock and Food Supply (MAPA) consider as the gold standard for diagnosing EIA [4]-[7]. Indeed, the OIE recommends the test for international trade [3]. In Brazil, this test is only required in laboratories that receive accreditation from MAPA, which is essential for the transit of animals within the country [4]. There is some disagreement between the protocols established by the OIE and MAPA to diagnose EIA, especially in relation to the volume of the reagents (i.e. 25 or $50 \mu \mathrm{L}$ ) and the support (i.e. slides or Petri dishes) for the agar gel used. Among these discrepancies, OIE recommends the use of Petri dishes measuring $100 \mathrm{~mm}$ in diameter, gel volume to $1 \%$, between 15 and $17 \mathrm{~mL}$ and the use of reagents by volume of $50 \mu \mathrm{L}$. MAPA protocol recommends using microscope slides measuring $25 \mathrm{~mm} \times 75 \mathrm{~mm}$, gel volume to $1 \%$ of $4.5 \mathrm{~mL}$ and the use of reagents by volume of $25 \mu \mathrm{L}$.

Therefore, the aim of the present study was to determine whether these differences between the protocols (OIE and MAPA) could affect the quality and interpretation of results using a comparative study and Equidae serum samples.

\section{Materials and Methods}

\subsection{Samples}

Serum samples $(\mathrm{n}=1000$ ) of Equidae (horse, asinine and mules) were provided by the serum bank of the National Animal and Plant Laboratory (Lanagro/PE) for use in the present study. Of the 1000 samples, 769 were positive, 136 were negative and 95 were negative with unspecific lines for EIA. Of the 769 positives, 50 samples were positive serum of reference. These samples were collected by the official veterinary service on different farms located in the northeast region of Brazil. All sera were stored at $-20^{\circ} \mathrm{C}$ until processing, which involved simultaneous analysis using the AGID test.

The reactions were performed using different volumes of reagents, as recommended by MAPA $(25 \mu \mathrm{L})$ and the OIE $(50 \mu \mathrm{L})$. A national commercial kit was used. This kit is based on purified antigen p26 from a nonpathogenic sample of EIAV.

\subsection{Agar Gel Immune-Diffusion (AGID)}

To prepare the agar gel, $1 \%$ noble agar was added to borate buffer ( 9 grams of boric acid and $2 \mathrm{~g}$ of sodium hydroxide diluted in $1000 \mathrm{ml}$ of distilled water $\mathrm{pH} 8.5$ - 8.7) and heated until the agar was completely melted. After cooling (about $\left.45^{\circ} \mathrm{C}\right) 4.5 \mathrm{ml}$ of gel were distributed on microscope slides $(25 \mathrm{~mm} \times 75 \mathrm{~mm})$ and $17 \mathrm{ml}$ was placed on a Petri dish (100 mm of diameter). After solidification, wells measuring $4 \mathrm{~mm}$ in diameter were made in the gel, with each well positioned $3 \mathrm{~mm}$ from the next. Afterwards, test and standard sera were distributed in the peripheral wells and the central well was filled with the antigen. Reagent volumes of $25 \mu \mathrm{l}$ and $50 \mu \mathrm{l}$ were tested on the slides, whereas only $25 \mu \mathrm{L}$ was used with the Petri dishes. The slides and Petri dishes were incubated in a humid chamber for 48 hours at $20^{\circ} \mathrm{C}-25^{\circ} \mathrm{C}$. Finally, the test reading was performed by two independent operators under a light source. The results of both operators were compared (based on the intensity of the reaction between the antigen and sera) to assess the performance of the test [8].

\subsection{Basis of the Serological Technique of AGID}

The AGID technique is based on the radial migration of the antigen-antibody (Ag-Ab) complex via the agar gel. The interaction between reagents in optimal proportions enables the formation of Ag-Ab complexes, which are insoluble and precipitate. The precipitation of these complexes creates dense lines, which are visible as a line or 
a band of precipitation. The presence of Ag-Ab in different concentrations can inhibit or alter the site of formation of the line. The proof was based on the formation of the line along the standard serum, which can be viewed by the naked eye, or with the aid of a light source [8] [9].

\subsection{AGID Reading and Interpretation}

A result was considered negative when the lines of the Ag and the positive control are directed in divergent directions, i.e. towards the well containing the sample test. In positive samples, the lines formed between the Ag and the positive control are fused with those formed by the samples test, forming a continuous line. Finally, samples are weakly positive when the precipitation line tends to be formed near the well containing the sample test.

In cases of low Ab titers, only the convergence of the two control lines towards the well containing the serum test can be visualized. The line of precipitation of a sample with high Ab titers (strongly positive) exhibits a diffuse band between the two lines of the control. In some situations, the formation of this band may be inhibited. In this case, only the two control lines, which were interrupted at the same distance from the serum test, can be visualized. In addition, no precipitation was observed between these lines. Strongly positive samples should be diluted in borate buffer and retested at the following dilutions: $1 / 4$ and 1/8.

The non-specific line is viewed when there is no formation of a continuous line with those of the control. These lines are formed by non-specific Ag-Ab reactions. It is known that a sample may produce a specific reaction (EIA positive) and a non-specific precipitation line [8].

\subsection{Data Analyses}

Data were added to contingency tables. The calculations of observed proportion (OP) and expected proportion (EP) were performed according to the methodology described by [10]. The Kappa index was used to characterize the agreement between the diagnostic tests and between the operators [11].

\section{Results}

The results were analyzed 48 hours after the beginning of the test. According to the intensity of the line formed between the antigen and serum tests, the samples were classified as follows: positive $(+)$, positive $(++)$, positive $(+++)$, positive $(++++)$, negative $(-)$ and negative with unspecific lines (-LI) (Figure 1(a) and Figure 1(b)).

The interpretation of the AGID results with $25 \mu \mathrm{L}$ and $50 \mu \mathrm{L}$ confirmed a complete agreement between the operators (Table 1). The AGID using $25 \mu \mathrm{L}$ of reagents exhibited sensitivity, specificity, positive predictive value and negative predictive value of $100 \%$, when compared with the AGID using $50 \mu \mathrm{L}$ of reagents (Table 2). After calculating the observed and expected proportions of agreement, a Kappa value of 1 was obtained, indicating an almost perfect agreement [11].

The use of $25 \mu \mathrm{L}$ of reagents did not affect the results of the test. The same result was obtained when test and standard sera and antigens were used with $25 \mu \mathrm{L}$ and $50 \mu \mathrm{L}$ of reagents (Figure 2). Regarding the use of different supports (slide or Petri dishes) for the gel (Figure 3(a) and Figure 3(b)), no difference was observed, with both supports exhibiting satisfactory results (Table 3 ).

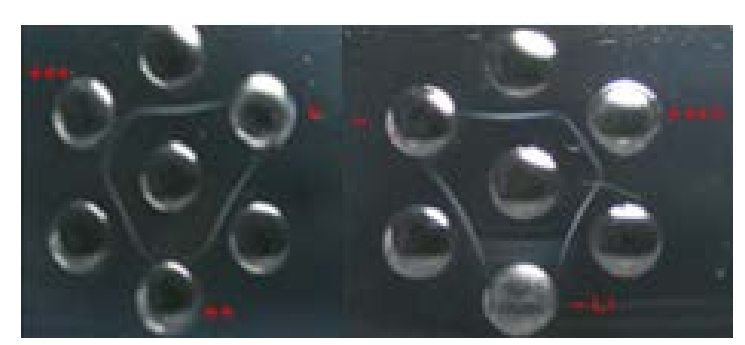

(a)

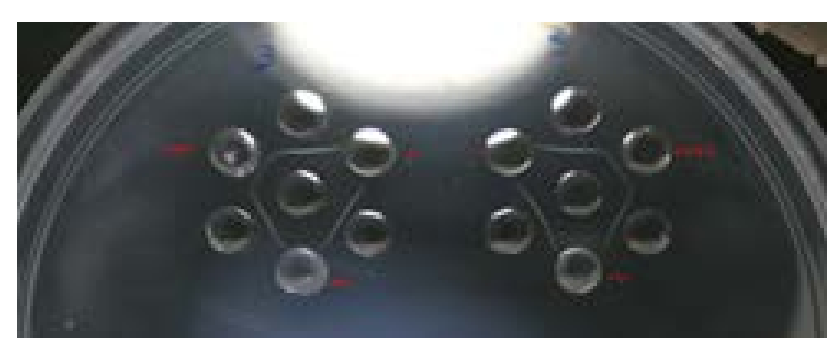

(b)

Figure 1. Classification of the samples based on the intensity of the reaction observed in the AGID test. (a) The slide presents positive samples with different intensities, being classified as,,,++++++++++ , a negative with unspecific lines and negative; (b) The Petri dishes presents positive samples with different intensities, being classified as,,,++++++++++ , a negative with unspecific lines and negative. 
Table 1. Comparison of the test readings performed by both operators using $25 \mu \mathrm{L}$ and $50 \mu \mathrm{L}$ of the reagents.

\begin{tabular}{ccccccccccc}
\hline \multirow{2}{*}{ Volumes } & \multicolumn{2}{c}{ Positive $(+)$} & \multicolumn{2}{c}{ Positive $(++)$} & \multicolumn{2}{c}{ Positive $(+++)$} & \multicolumn{2}{c}{ Positive (++++) } & \multicolumn{2}{c}{ Negative (-) } \\
\cline { 2 - 11 } & $25 \mu \mathrm{L}$ & $50 \mu \mathrm{L}$ & $25 \mu \mathrm{L}$ & $50 \mu \mathrm{L}$ & $25 \mu \mathrm{L}$ & $50 \mu \mathrm{L}$ & $25 \mu \mathrm{L}$ & $50 \mu \mathrm{L}$ & $25 \mu \mathrm{L}$ & $50 \mu \mathrm{L}$ \\
\hline Operator 1 & 206 & 206 & 225 & 225 & 178 & 178 & 160 & 160 & $231^{*}$ & $231^{*}$ \\
Operator 2 & 206 & 206 & 225 & 225 & 178 & 178 & 160 & 160 & $231^{*}$ & $231^{*}$ \\
\hline
\end{tabular}

${ }^{*}$ Negative samples $=136$; negative samples with unspecific line $=95$, total of negative samples $=231$.

Table 2. Comparison of the results of the AGID test using 25 $\mu \mathrm{L}$ and $50 \mu \mathrm{L}$ of the reagents.

\begin{tabular}{cccc}
\hline \multirow{2}{*}{ AGID $(50 \mu \mathrm{L})$} & \multicolumn{2}{c}{ AGID $(25 \mu \mathrm{L})$} & Total \\
\cline { 2 - 3 } & Positive & Negative & \\
\hline Positive & 769 & 0 & 769 \\
Negative & 0 & 231 & 231 \\
Total & 769 & 231 & 1000 \\
\hline
\end{tabular}

Table 3. Comparison of the results of the AGID test using slides and Petri dishes.

\begin{tabular}{cccc}
\hline \multirow{2}{*}{ Slides } & \multicolumn{2}{c}{ Petri dishes } & Total \\
\cline { 2 - 3 } & Positive & Negative & \\
\hline Positive & 769 & 0 & 769 \\
Negative & 0 & 231 & 231 \\
Total & 769 & 231 & 1000 \\
\hline
\end{tabular}

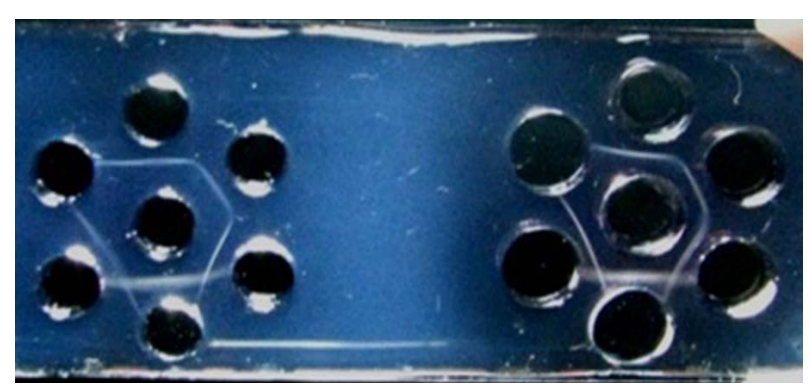

(a)

(b)

Figure 2. Comparison of the results of the AGID test using $25 \mu \mathrm{L}$ (a) and $50 \mu \mathrm{L}$ of the reagents (b).

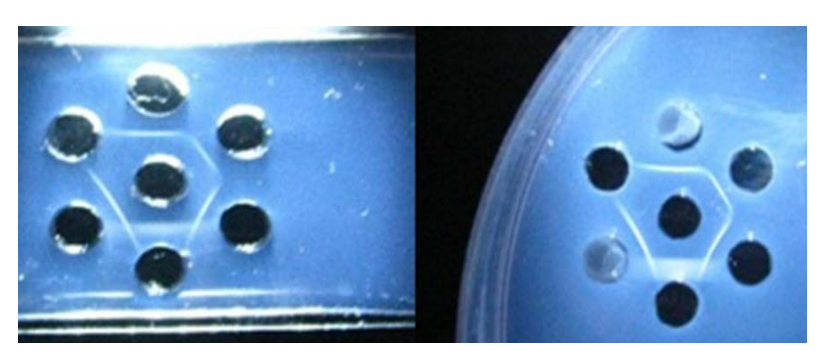

(a)

(b)

Figure 3. Comparison of the results of the AGID test using slides, Petri dishes, and $25 \mu \mathrm{l}$ of sera and reagents. (a) Slide; (b) Petri dishes. 
The AGID test using Petri dishes exhibited sensitivity, specificity, positive predictive value and negative predictive value of $100 \%$, when compared with the AGID test using slides as support. After calculating the observed and expected proportions of agreement, a Kappa value of 1.0 was obtained, indicating an almost perfect agreement [11].

\section{Discussion}

The present study compared two protocols of the AGID test (as recommended by MAPA and OIE). Sera samples $(n=1000)$ were tested and agreement of $100 \%$ was observed between the protocols analyzed and between the operators. Considering the similar results, both protocols (MAPA or OIE) can be used to diagnose EIA.

In fact, the use of antigens and sera in reduced volumes could represent an advantage, especially in terms of the reduction of costs, since the number of tests can double without additional costs. However, considering the use of slides or Petri dishes, no difference was observed during the performance of the test or the interpretation of the results. Therefore, the choice of the support to be used with the agar gel should be made by the operator.

One advantage of the Petri dish is that a higher number of samples cab be placed in a small incubation chamber, since the Petri dishes can be stacked one above the other. During the test, the Petri dishes were easier to handle and there was no risk of deforming the gel layer with pressure from the fingers. In addition, there was a reduction in the dehydration of the gel layer, which normally occurs at the edges of the slide.

Few studies comparing volumes of reagents of IDGA to EIA were made. Regarding the media used in the IDGA tests, both the microscope slides as the Petri dishes, there are not finds scientific papers related to the theme. Oliveira [12] developed the IDGA according to the OIE protocol, testing 345 equine samples. Out of 344 samples, 244 resulted negative and 100 positive. In our study, one sample had false negative result with the imported kit. In the same study, testing the kit imported by the MAPA protocol, of the 345 samples analyzed, 04 were detected as false negatives.

\section{Conclusion}

By offering a reading and interpretation of similar quality results in IDGA tests for the diagnosis of AIE, the volume of antigen, standard serum and serum test may be used according to the amount established by MAPA $(25 \mu \mathrm{L})$ or as recommended by OIE $(50 \mu \mathrm{L})$. There are not differences between the use of slides or Petri dishes. It is not significant in reading the results, suggesting the use of two ways in according to the MAPA or OIE.

\section{Acknowledgements}

The authors of the present study would like to thank the Ministry of Agriculture, Livestock and Food Supply, the National Council for Scientific and Technological Development (CNPq), and the Laboratory of Virology of the National Animal and Plant Laboratory (LANAGRO/PE), as well as their staff.

\section{Authors' Declaration of Interests}

The authors and other workers declare not conflict of interest.

\section{References}

[1] Issel, C.J. and Coggins, L. (1979) Equine Infectious Anemia: Current Knowledge. Journal of the American Veterinary Medical Association, 174, 727-733.

[2] Van Regenmortel, M.H., Mayo, M.A., Fauquet, C.M. and Maniloff, J. (2000) Virus Nomenclature: Consensus versus Chaos. Archives of Virology, 145, 2227-2232. http://dx.doi.org/10.1007/s007050070053

[3] World Organization for Animal Health (OIE) (2013) Equine Infectious Anaemia. In: Manual of Diagnostic Test and Vaccines for Terrestrial Animals (Mammals, Birds and Bees), Paris, 866-870.

[4] Brasil (2008) Ministério da Agricultura, Pecuária e Abastecimento. Instrução Normativa nº 15, de 02 de abril de 2008. Diário Oficial da União, nº 65, Seção 1, 2.

[5] Matsushita, T., Hesterberg, L.K., Porter, J.P., Smith, B.J. and Newman, L.E. (1989) Comparison of Diagnostic Tests for the Detection of Equine Infectious Anemia Antibody. Journal of Veterinary Diagnostic Investigation, 1, 50-52. http://dx.doi.org/10.1177/104063878900100114 
[6] Alvarez, I., Gutierrez, G., Vissani, A., Rodriguez, S., Barrandeguy, M. and Trono, K. (2007) Standardization and Validation of an Agar Gel Immunodiffusion Test for the Diagnosis of Equine Infectious Anemia Using a Recombinant p26 Antigen. Veterinary Microbiology, 121, 344-351. http://dx.doi.org/10.1016/j.vetmic.2007.01.007

[7] Piza, A.S.T., Pereira, A.R., Terreran, M.T., Mozzer, O., Tanuri, A., Brandão, P.E. and Richtzenhain, L.J. (2007) Serodiagnosis of Equine Infectious Anemia by Agar Gel Immunodiffusion and ELISA Using a Recombinant p26 Viral Protein Expressed in Escherichia coli as Antigen. Preventive Veterinary Medicine, 78, 239-245. http://dx.doi.org/10.1016/j.prevetmed.2006.10.009

[8] Brasil (1992) Portaria $n^{\circ}$ 84, de 19 de outubro de 1992. Aprova as normas de credenciamento e monitoramento de laboratórios de anemia infecciosa equina-AIE. Diário Oficial da República Federativa do Brasil, SDA, Brasília, DF 22 de outubro, seção 1, 14874-14876.

[9] Flores, E.F. (2007) Virologia Veterinária. Editora UFSM, Santa Maria.

[10] Pereira, M.G. (1999) Epidemiologia: Teoria e prática. Guanabara Koogan, Rio de Janeiro.

[11] Landis, J.R. and Koch, G.G. (1977) The Measurement of Observer Agreement for Categorical Data. Biometric, 33, 159-174. http://dx.doi.org/10.2307/2529310

[12] Oliveira, F.G. (1984) Validação da imunodifusão em gel de Agar para diagnóstico da anemia infecciosa equine em equídeos e comparação com o ELISA rgp90 e immunoblot. Dissertação UFMG, 55 p. 